상징과모래놀이치료, 제 10 권 제 2 호

Journal of Symbols \& Sandplay Therapy

2019, 12, Vol. 10, No. 2, 1-18.

\title{
Jar: The Space of Transformation to Self-Actualization
}

\author{
Soo Kyung Kwak*
}

\begin{abstract}
$<$ Abstract $>$
The image of the jar has emerged in various cultural contexts. The purpose of our study is to understand its symbolic meaning. We examined it from the perspective of analytical psychology. This involved an analysis of the manufacturing procedure and function. We also studied stories of jars such as Sikjang Mountain folktale and the Marriage at Cana of the New Testament, and the architectural works related to Buddha's Sarira. We find that it serves as a symbol of the space in which the psyche can achieve self-actualization.
\end{abstract}

Keywords : jar, symbolism, transformation, self-actualization, ego-self axis

* Therapist, Sandplay therapy at Maeumgyul Shelter (zskwak@naver.com) 
Journal of Symbols \& Sandplay Therapy, Vol.10 No.2.

\section{I . Introduction}

The moon jar, a distinctive type of white porcelain from the late Joseon period1), is evaluated as successfully embodying the unique, traditional aesthetics of Korea (Yoon, 2000). Because the moon jar is rather large, the upper and lower parts are produced separately and joined in the middle. Therefore, the bulge around the center that marks the join between the two halves looks different according to whom the creator is. Kim, Whan-Ki, a guru of Korean modern arts, made the following statements about moon jars: "The jars are cold yet emit warm steam. They are all white in color, but in different tones" (Kim, 2005). "The simple circular shape and white hue are complex and delicate, radiating mysterious beauty. Within stillness, there is movement and speed" (Kim, 1999, as cited in Lee, 2005). Capturing the beauty formed by integrating opposite images, Kim established himself as an artist who gave body to traditional Korean sentiments through his unique style (Park, 2010).

Similar images can be seen not only in moon jars but also in hangaris2)- hereinafter referred to as "jars" - that are used to store doenjang3). Doenjang goes through a primary fermenting process, which involves making lumps of fermented soybeans called meju, then a secondary fermenting process, where the fermented soybean lumps are stored in jars for maturing. The process is seemingly quiet and peaceful. Yet looking closely, the process of maturing also involves dynamism and uncertainty. Edinger (1984/2016) said that the union of opposites is often painful, using the metaphor of crucifixion. Nevertheless, the reason why the maturing process appears peaceful may be that jars have an image of gently and safely containing the unstable situation.

Rhi (2011) explained that archetypes are the most basic behavioral pattern of human beings and the energy that comprises the collective unconscious. Because archetypes become activated for a certain purpose, when necessary, they become constellated in the unconscious, become conscious and therefore experienced. Archetypes are experienced to overcome the situation in which the conscious becomes separated from the unconscious due to unilateral

1) A Korean dynastic kingdom that lasted from 1392 to 1897.

2) Traditional Korean clay jars used to help the fermentation in food processing of condiments.

3) A type of fermented bean paste made entirely of soybean and brine. 
development of the conscious. We see their existence in the world of mythologies or folktales (Rhi, 2011). According to Tuner (2005/2009), symbols become manifested as archetypal images from the unconscious when the ego faces an adaptation crisis. Kalff (2012) also said that to overcome the separation of the conscious from the unconscious, one must go through the process of making the unconscious conscious. Making the unconscious conscious requires a safe space (Kalff, 2012). The image of containment shown in moon jars or jars that store doenjang implies that jars can symbolically become that safe space in which the unconscious would become conscious.

Aside from being a symbol of containment as mentioned above, existing studies have also identified other symbolisms of jars: sacredness, maternity and the feminine, death and revival, expectation and hope, maturity and transformation, container, and so on (Seo, 2019). The manufacturing process and functionalities of jars as well as symbolisms of the basic materials in part two of this paper, and various symbolisms of jars in different cultures in part three are in line with the outcome of existing studies. Furthermore, this study seeks to find common elements that encompass these various symbolisms, and use the logic in literatures of analytics psychology to this end.

As mentioned already, the symbolisms of jars were apparent in different cultures in order to bring the unconscious to consciousness, which is an attempt to overcome the separation of the conscious from the unconscious (Kalff, 2012). By exploring the types of unconscious that were expressed through the symbolisms of jars, the paper will try to understand the roles that they played in various cultures up to today.

\section{Characteristics Of Jars}

\section{Symbolisms in the Process of Jar Creation}

According to Bang, Byung-Sun (2002), Korean earthenware jars are made first by mixing soil with water. The dirt dough is beat until it becomes soft. Then, using various 
Journal of Symbols \& Sandplay Therapy, Vol.10 No.2.

techniques, the dough is formed into a desired shape and then slowly dried. Once the clay dries completely, it is put in the kiln at 850-900 degree Celsius. While the kiln varied in its form throughout different time periods, traditional kilns were made of clay or brick. After the jar is fired in the kiln for the first time, glaze is applied to make the surface shiny and to prevent water from infiltrating. Afterwards, it is put in the kiln to be fired again at 1,250-1,300 degrees Celsius. But even after this meticulous process, jars that have flaw would be discarded. Having to go through the process of being beaten, exposed to high-temperature heat inside a kiln, and sometimes broken, jars experience descent and rebirth.

Creation of jars involves the transformation of earth through water and fire, which is similar to the alchemical process. First, earth, a symbol of mother goddess or the pregnant mother, is the prima materia. Earth is completely mixed with water the uterus of the universe - becoming soft clay (Cooper, 1978/1994). While earth and water may be similar in terms of their symbolic meanings, their physical properties are distinctly different. These disparate materials are mixed and beat until their differences become indistinguishable. Then the potter fashions the clay to create different shapes. These creations then have to encounters fire: a symbol of transformation, purification, or rebirth (Cooper, 1978/1994). This is akin to the alchemical process of washing, distilling and purifying the basic material in a closed container to dispose of heavy materials (Rhi, 2002). Once the impurities in the clay are purified by fire in the kiln, a jar the crystallization of the pure feminine-is created.

We ought to also pay attention to the fact that the kiln, the space in which the clay-based creation meets fire, is also made with clay or bricks. How a kiln, made of feminine soil and water, purifies itself through heat and therefore creates clay pot composed of soil and water reminds us of a quote from an ancient text: "He found foothold on the earth. When he had found a firm foothold there, he thought: I will propagate myself. He emitted heat and became pregnant." We can also make a reference to Neumann's comment: "The maternal side of the uroboros gives birth without procreation" (2004/2010). The kiln, having the maternal side of the uroboros, provides a space in which clay-based substances become transformed through the process of purification and is born again as the crystallization of the feminine. Jung explained that the Self is the unconscious foreshadowing of the ego (Jung, 1958, as cited 
in Edinger, 1972/2016). Thus it is natural for a jar, created through the same process, to have a symbolism of the receptive feminine (Cooper, 1978/1994). A jar that has gained the same symbolism as the kiln and is completely separated out of it becomes a symbols of an ideal ego-Self axis.

\section{Symbolisms in the Functions of Jars}

Jars, made from the kiln of uroboros, become vessels. Vessels contain and store various things like grain, oil, kimchi, and various condiments. In some cases, feces that will be used as fertilizer are stored in a vessel. In the ancient days, people stored organs of the dead inside a vessel with the hopes that the dead would be reborn. Looking at the containing function of jars, it is easy to understand that one of its symbolisms is the receptive feminine (Cooper, 1978/1994). A deeper observation, however, allows us to realize that jars do not just contain but also transform the material within. Materials stored inside jars become something entirely different once they come out of the jars. In other words, one of the functions of a jar is to bring transformation to substances stored inside. A prime example would be the transformation of soybean and salt into doenjang.

Jars enable the contents stored within to become fermented as it has the function to "breathe." Using natural glaze, jars block water but allow air to penetrate. In other words, jars block outside elements but at the same time are still influenced by them. And while they are an inanimate object by nature, they have the characteristics of an organism. This reminds us of self-actualization expressed through the "philosopher's stone," which is metallic yet liquid, matter yet spirit, cold yet fiery, poison and yet healing and therefore is the symbol of the union of the opposites (Rhi, 2002). The Self contains the opposites; it accepts and experiences the opposites and their conflicts and therefore reaches the wholeness of the psyche (Rhi, 2002). Thus we can see that the functions of the opposites contain and accept soybeans and salt and allow jars to reach the Self. The outcome of overcoming the opposites and reaching the Self is the birth of the news conscious, which was referred to as the "transcendental function" by Jung (Rhi, 2002). Referring to the metaphor of doenjang again, this would be the process in which there is union between soybeans and salt and they become reborn, through the 
Journal of Symbols \& Sandplay Therapy, Vol.10 No.2.

transcendental function, as doenjang. Therefore, a quality jar that ideally performs the function of achieving self-actualization by uniting the opposite can produce ideal doenjang.

The process in which soybeans and salt are transformed into doenjang while being stored in jars can be metaphorically described by the development of the consciousness, as explained by Neumann (2004/2010). The clay jar would represent the maternal aspect of the earth. Meju, the substance stored inside the jar, would represent the mythical phallic youths, vegetation that sprung up from the earth but not separated from the Mother. Filling the jar storing meju again with brine is like creating the ocean, a symbol of the Great Mother, and thus can be seen as an attempt to expand the feminine aspect of the jar (Cooper, 1978/1994). The phallic youths are dismembered as the sacrificial offering in a fertility ritual for the Great Mother (Neumann, 2004/2010). Likewise, the soybeans and salt inside a jar is also "dismembered," losing its original form. These dismembered youths are born again by the Great Mother, and they gradually begin the attempt to separate their ego and consciousness from the unconscious and the Great Mother (Neumann, 2004/2010). But they are still not strong enough to gain victory, and turn against themselves in self-destruction and self-mutilation. At this time, the positive mother aspect of the Great Mother makes an intervention: It makes whole and new, reduces the broken pieces to unity, gives new form and new life to the corruptible and leads beyond death (Neumann, 2004/2010). This process is similar to what happens inside a jar. While meju and the jar are separate entities, meju also becomes a part of the jar while being stored. The space within the jar becomes a place to be torn apart and at the same time a place where it receives protection from the mother. By repeatedly going through the process of dismemberment, self-destruction and rebirth, meju is transformed into a new being, just as the phallic youths become adults in mythology. Once it reaches consciousness to become an independent being, without having to depend on the maternal jar, meju has transformed into doenjang, fully ready to come out of the jar. 


\section{Jars In Different Cultures}

Building on the characteristics of jars seen from the lens of analytical psychology, this part of the paper seeks to examine various symbolisms that appear in different cultures by looking into the Tale of Sikjang Mountain, the story of Marriage at Cana in the New Testament, and stupas in Buddhist temples. A common symbolism of jars that appear in these three cases is that they provide "a safe, containing space that allows transformation toward self-actualization". The following sections examine each story in detail:

\section{Tale of Sikjang Mountain}

A book of folktales written by Min, Yoon-Sik (2005) titled A Hundred Fun Old Stories Told by Our Grandmothers features a legend about the Sikjang Mountain, which is stretches across the border between Daejeon Metropolitan City and Okcheon county in North Chungcheong province. Once upon a time, at the foot of a mountain, a devoted son and his wife lived together with his old mother and their young child. The family was very poor. The couple provided the mother with everything she liked. But as the child grew older, he began to eat the old mother's food and the couple faced trouble in providing for her. After long thought, the couple decided to take the child to the mountain and bury him in the ground. As the couple began to dig the ground with a pick, they discovered a strange jar. Staring at the jar, the wife teared up and said she will take the child outside whenever the old mother is eating. She wanted to save the child and at the same time carry out her filial duty. The husband agreed, and the couple brought the child and the jar back home. At home, the couple cleaned the jar and put a handful of rice in it. After a while, the couple opened the lid and much to their surprise, the jar was filled with rice. Amazed, the couple put a couple of coins inside the jar and the jar soon was overflowing with coins. Thinking that the jar was a gift from heaven to serve the old mother well, the couple decided that they would use it only while the mother lived. Since then, the couple worked diligently and their living condition gradually improved even without help from the jar, and they soon became rich. Even so, the 
Journal of Symbols \& Sandplay Therapy, Vol.10 No.2.

couple never became greedy and lived diligently. After the mother passed away, they buried the jar where they first found it. Since then, people began to call the mountain Sikjang (rice-storing) Mountain or Sikgi (vessel) Mountain.

In modern times, it is hard to accept the decision of the couple. It may be regarded as an unsophisticated story created by someone from the Joseon dynasty, an era which placed great emphasis on filial piety, for educational purpose. But if the story was made only with a certain intention, it would not be told until today. Folktales are not created by conscious intention; Rather, it is a collaborative work in which the framework of the story is shaped and refined as it travels from mouth to mouth through the unconscious (Lee, 2010). Therefore, this folktale is still told until today because it conveys some wisdom from the collective unconscious that could still be applied today.

In order to find the unconscious wisdom in this folktale, let's first look at the characters. The devoted son can be seen as the kinship libido as mentioned by Jung. In other words, it is a state in which an individual stays in the ancient bond of a close family relationship (Jung, as cited in Neumann, 2004/2010). The son's old mother represents the Great Mother. When individuals grow, they become independent from the parent and form a new family. This process, however, involves anxiety as stability has to be broken down to bring about changes. So in some cases, it may look easier to just stay in the Great Mother instead of undergoing changes. This would be the state in which an individual's psyche stays in the uroboros or even experiences regression. The symbol of choosing regression appears in the fairy tale "The Heavenly Maiden and the Wood Cutter" (Lee, 2010). After going through all sorts of hardships, the wood cutter finally managed to meet his heavenly maiden wife who returned to heaven. But he spilled the pumpkin porridge his mother had made on the winged-horse, and the horse knocked the woodcutter to the ground and flied away to the sky. Thus the wood cutter was separated from his wife forever. The wood cutter represents the psyche that was not able to separate from the Great Mother, similar to the case of devoted son during the initial part of the tale.

Neumann (2004/2010) explained when a hero in mythology faces danger, a female figure for example, his sister - is willing to make sacrifice with her devoted love. While the 
wide of the tale did not fight back by putting her life at risk or making sacrifices, she found a way for the old mother and child to live together which did not occur to her husband. When we remind ourselves that slaying of the dragon in mythology does not only mean dismantlement but also assimilation (Neumann, 2004/2010), the contribution made by the wife becomes clear. The liberation of female prisoners represents the separation of the young feminine, often portrayed as a maiden or wife, from uroboric mother (Neumann, 2004/2010). The moment the wife, or the young feminine, broke away from the state of unconditionally supporting the old mother and offered a way for her child and the mother to live together was when the anima overcame the Great Mother. In other words, the young feminine separate from the threatening world of the unconscious dominated by the mother and developed into anima (Neumann, 2004/2010). This moment was also depicted in the scene where the buried jar was unearthed.

Though not told in the tale, the devoted son couple probably had worked diligently even before discovering the jar. But the fact that they became rich after finding the jar is consistent with the psychological interpretation that anima is the source of abundance (Neumann, 2004/2010). Also the fact that the couple became rich after the wife voiced her opinion clearly shows that not only the jar but also the wife is the symbol of anima, which is the source of abundance.

After the wife's suggestion, or, after the anima liberated from the Great Mother, the son established new rules and supported both his mother and child. This represents the beginning of paternal authority, with the help of the containing function of the anima. The beginning of paternal authority means that men are now able to look over their own children independently (Neumann, 2004/2010). It is not easy, however, to be completely free from the influence of the mother. Continued assistance from the anima is necessary to be fully separated from the mother. This was the case for Perseus, who defeated the monster with the help of Hermes and Athena (Neumann, 2004/2010). In the tale of Sikjang Mountain, the son also needed continued help from the jar and his wife. Just as the jar continued to provide necessities in life and the wife continued to work hard, the development of consciousness toward the continuity of the ego and stability of the conscious occurs gradually with continued 
Journal of Symbols \& Sandplay Therapy, Vol.10 No.2.

help from the anima. The development of consciousness continues until there is complete liberation and separation from the Great Mother. Likewise, the son continued to receive help from the jar and his wife until his mother died. Then the jar, which carried out its function of containment so that the son can enter into an era of patriarchal authority and establish new rules, returned back to the ground where it was originally found.

\section{Marriage at Cana}

"Marriage at Cana," which appears in Chapter 2, verses 1-12 in the Gospel of John is an account in which Jesus begins his first public career. Jesus and his disciples are invited to a marriage feast and the party ran out of wine. Hearing this, Jesus' mother indirectly asked Him to resolve the problem and Jesus replied, "Oh Woman, what has this to do with me? My hour has not yet come." His mother then said to the servants, "Do whatever he tells you." Jesus ordered the servants to fill six stone jars, which were there for the Jewish ritual washing, with water and to draw out some and take it to the chief steward. After tasting it, without knowing where it came from, the steward remarked to the bridegroom that he had departed from the custom of serving the best wine first by serving it last.

Marriage is a system where men and women unite to form a new family. In Christianity, marriage is symbolically considered as a union of Christ and His believers, or the union of the church (Henry, 2006). It is also used as a symbol of union in various disciplines, including analytical psychology. Wine symbolizes blood, as explained by Jesus to his disciplines during the Last Supper in Matthew 26:28: "This is my blood of the covenant, which is poured out for many for the forgiveness of sins." The blood of the covenant also appears in the Old Testament when the Old Covenant was established between God and the people of Israel. We can see that from the ancient days, blood had a divine meaning, was identified with life and was used to represent the covenant between divine power and humanity (Edinger, 1972/2016). In other words, the marriage feast in this story holds the same meaning as the covenant with God in the Old Testament, and wine can be seen as the blood that validates this covenant.

After Adam ate the forbidden fruit in the Garden of Eden, his ego became separated from the womb of the Self, which is the Garden (Edinger, 1972/2016). Then the separated ego 
entered into covenant with God through animal blood, thereby forming the ego-Self axis. But the fact that there was not enough wine at the wedding means that the covenant, which is the foundation for this axis, is in danger of losing its effect. Without wine, the wedding feast would be ruined. Likewise, without blood the covenant could not be maintained. The bride and the groom in this story are at the risk of losing the union with God and getting their marriage ceremony ruined. And just like all heroes in mythologies, they manage to get help from someone else to become aware of the damaged ego-Self axis. Here, Jesus played the role of a divine figure who performs the task of rescue through the miracle of turning water into wine (Jung, as cited in Edinger, 1972/2016).

This event is all the more significant as this was the first public miracle that Jesus performed as the Son of God. As if to sum up what Jesus will do in the future (Kang, 2013), the first miracle revealed the problem between God and human beings and at the same time suggested a solution by creating wine that represents His blood. Edinger considered the Self as the identification with the god-image and said the goal of self-actualization is to achieve conscious relationship with one's Self (1972/2016). Before Jesus, people showed hostility toward the prophets sent by God and were drifting apart from Him; In other words, they were compromising their conscious relationship with the Self. When the ego-Self axis became compromised and the human covenant with God was at risk of becoming ineffective, Jesus, the divine being who carries out the work of salvation, supplied blood through the jar so as to keep the covenant effective.

In regard to Jesus' first miracle, Diel \& Solotareff (1988) argued that the real reason for Jesus' death was the breaking of the ethical practice, represented by the water and jars used for Jewish ritual washing. They suggested that there was an intention to disintegrate the union of water and jar to facilitate transformation into something else (Jeong, 2003), connecting this incident with death on the cross, the last part of His public career.

However, John 19:34 records that when a soldiers took a spear and pierced Jesus' side after his death, blood and water gushed out. We have so far analyzed water as something incomplete that has to be turned into wine. However, water appears together with wine in the last part of his public career, which may raise doubts over the initial analysis. For clarification 
Journal of Symbols \& Sandplay Therapy, Vol.10 No.2.

purposes, perhaps theological discussions on blood and water from Jesus' side ought to be examined. Some theologians believe that the blood and water represent two sacramentsCommunion and baptism, respectively when connecting the early worship ceremony of Christianity and the life of Jesus Christ (Cullmann, as cited in Han, 2003). Even if the blood from Jesus' side can connected with the wine used in the Communion, there is little ground to link water to baptism (Carson, 1991/2017). Others suggest that the event is a fulfillment of the prophecy from the Old Testament: "Not one of his bones will be broken." The water would represent the transparent plasma that is separated from blood two to four hours after one's death, and hence the blood and water imply that Jesus was already dead (Beasley-Murray, 2001, as cited in Kim, 2019). In other words, it may be more reasonable see the water as an objective sign showing that Jesus has already died and as a symbol of the presence of a new Holy Spirit (Schnackenburg, as cited in Carson, 1991/2017). Hence, the water in John 19:34 has a different symbolic meaning than the water that had to be turned into wine. It is an outcome created as a result of Jesus' crucifixion.

The theological viewpoint which connects the miracle of water turning into wine to the death by crucifixion (Diel \& Solotareff, 1988, as cited in Jeong, 2003) can be explained through analytical psychology as well. According to Jung, the psyche of all human beings progress when the soul experiences pain (Edinger, 1972/2016). Jesus, who represents the jar metaphorically, endured pain on the cross and, as a result, water turned into blood. In other words, the significant transformation was made possible because of the pain Jesus suffered. Transformation is an outcome of enduring the opposites and accepting even the shadows within oneself. After Jesus suffered and accepted his pain, blood broke out of the jar -i.e., his body and made the covenant between God and humans valid. And the output of this valid covenant is the Holy Ghost (Schnackenburg, as cited in Carson, 1991/2017).

A similar image can be found in the manna jar, which was stored in the Ark of the Covenant symbolizing God's presence in the Old Testament. When the Israelites had to wander in the wilderness without food after fleeing from Egypt, God provided them with manna. The Israelites could enjoy manna for only one day. Whatever they hoarded would be spoiled the next day. The manna reminds us of the bread that Jesus shared with his disciples during the 
Last Supper, saying that it is his body. The manna jar and also the stone jars used at the wedding feast in Cana had to be washed to remove impurities and filled every morning with manna and water, respectively, which were effective only for a certain period. But after the jar, metaphorically represented by Jesus Christ, endured the pain and broke out of its body, the manna and the water becomes Jesus' body and blood through the validated Covenant. Thus, the body of the Jesus Christ is an enlarged version of the manna jar and the stone jar. It has the same symbolic meaning as the space that contained and protected the phallic youth, who was dismembered and repeatedly experienced death to be transformed into a powerful adult.

\section{Sarira Jars in Buddhist Temples}

Lee, Hee-Bong (2012) gave an explanation as to why the images of jars can be seen on dancheong(4) and munsal5) of Buddhist temples. Because water is precious in India, the water jar symbolizes a sacred being. For this reason, we can often see jar-shaped structures atop the spire of the Hindu temples. After Budda's Parinirvana, his body was cremated and the remaining bones and ashes were divided into eight equal portions among eight tribes, who stored the corporeal relics, or sarira, in a jar and erected stupas to enshrine them. These were the first stupas. Afterwards, followers of Buddha began to worship stupas, a culture which was brought into Korea. Even in Korea, corporeal relics are mostly kept in a sarira jar and then enshrined in a stupa. Images of these jars can be found in dancheongs of Korean Buddhist temples. In Figure 1, there is a pomegranate placed on a lotus-shaped base. At the tip of the pomegranate is a ball-shaped jar, which is out halfway, and at its end is a white dot. This dot represents an egg symbolizing the process of birth. We can see that life comes out of the jar, which contains the relics of Buddha. This image symbolizes Buddha's relics breaking out of the jar just as a new lift form is born out of an egg -and spreading across all nations on earth. The jar does not just have a static function to contain something precious, but also a dynamic function that allows truth to be spread across the world. In other words, the Buddha's corporeal relics symbolizes breaking out of the jar and spreading to all parts of the world as if

4) Traditional multicolored paintwork on wooden buildings

5) The frame of a sliding door 
Journal of Symbols \& Sandplay Therapy, Vol.10 No.2.

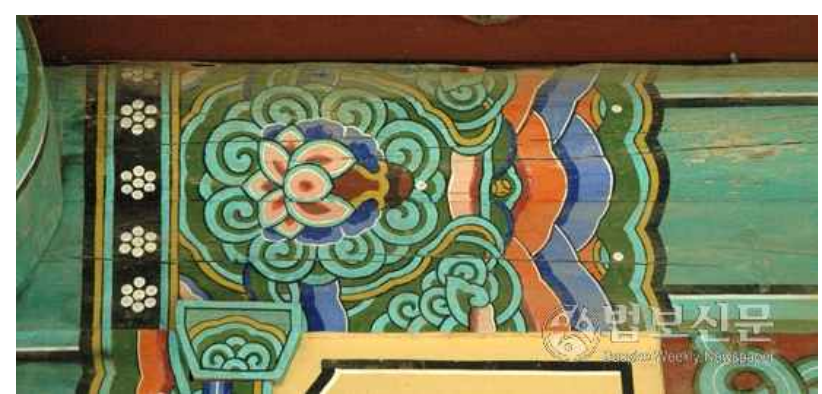

Figure 1. Image of dancheong, Bulyeong Temple in Uljin County (Source: Beopbo News)

breaking out of an egg. Rather than simply staying in the function of holding precious things, the Buddha's relics was transformed into a dynamic way of breaking eggs and spreading the truth to the world.

The munsal of a sanctuary is usually decorated with flowers. In Figure 2, the center part of the munsal in the sanctuary of Jeongsu Temple is painted with flowers spreading out from a base. These flowers in full bloom is a detailed articulation of the Buddhism truth spreading across the whole world. Images of such flower jars can be found in not only Indian Buddhist temples but also Hindu and Jain temples.

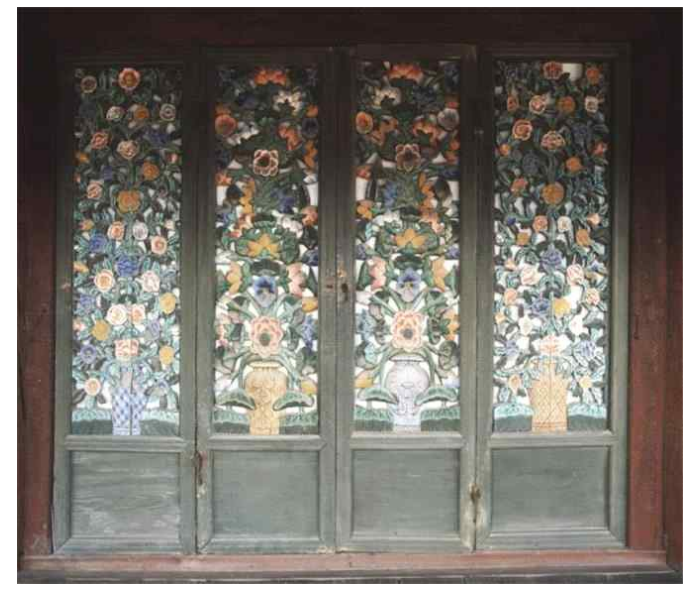

Figure 2. Image of Munsal, sanctuary in Jeongsu Temple

(C)Academy of Korean Studies, Yoo, Nam-hae) 
On the other hand, ancient Egyptians believed that the dead would resurrect in the underworld. Therefore, when Pharaoh died, the body was made into a mummy through a complex embalming ritual that took about 70 days (Ions, 2003). The heart was left in the body, but the stomach, liver, colon and lungs were stored in a canopy jar and buried with the mummy. The Egyptians at that time regarded death as a journey into the underworld, and thus buried whatever the dead would need in the new world in the grave: food, clothing, furniture, paintings, slaves figures, etc. (Ions, 2003).

This ancient Egyptian belief is closely connected to the image where the truths of Buddha's teachings come out from the jar to be spread across the world. Here, we can make a reference to the three stages in the rites of passage into adulthood in a primitive society: pain, death and rebirth (Rhi, 2002). The emergence of Buddhism truth and the rebirth of the Pharaoh from the jar can be seen as overcoming both pain and death and being reborn, therefore accomplishing self-actualization. Thus the jar provides the space of the Great Mother in which transformation toward self-actualization occurs. As mentioned already, the relics in the jar symbolize the phallic youths, who are repeatedly dismembered by the Great mother and born again according to Neumann's theory on the development of consciousness (2004/2010). The jar makes anew the phallic youths who remained in self-destruction and self-mutilationintegrating the broken pieces and shaping them into something new. In other words, jar gives life energy to overcome death (Neumann, 2004/2010). Overcoming of death by Buddha and Pharaoh represents the attainment of rebirth, the last stage of the rites of passage into adulthood, and separation from the Great Mother to ultimately achieve self-actualization. When the jar is broken that is, when Buddha's relics blossom in the world or when the Pharaoh safely passes through the twelve gates of the underworld and enters into the world of eternal life (Ions, 2003)-rebirth and self-actualization are attained.

\section{Conclusion}

This paper explored the manufacturing process of jars, symbolisms found in their 
Journal of Symbols \& Sandplay Therapy, Vol.10 No.2.

functionalities, and related tales as well as other cultural elements so as to analyze the symbolical meaning of jars from the viewpoint of analytical psychology. The base materials of a jar are earth and water, both a symbol of the feminine. After being formed into a certain shape using those materials, the jar is fired in a kiln and therefore goes through a process of purification. Through this process, the jar becomes the crystallization of the feminine and becomes a vessel with containing function. As can be seen in the fermentation of doenjang, things that are stored in the jar are dismantled until they lose their innate nature and become completely transformed before coming out of the jar. This process can be a symbol of the ego separating from the uroboric Self.

This study analyzed the images of jars that appear in the Tale of Sikjang Mountain, the Biblical story of a wedding at Cana, and sarira jars in Buddhist temples. In the Tale of Sikjang Mountain, the jar, which represented the anima separated from the uroboric mother, contained the psyche so as to facilitate its independence and allowed entry into an era of patriarchal authority in which new rules are established. In the story of the wedding at Cana, the jar allowed water to transform into blood, which enabled the covenant between God and man to be valid eternally and thus the ego-Self axis to be restored. In the example of the sarira jar, the image in which Buddha's corporeal relics break out of the jar and spread wisdom across all nations showed that the jar provide a space for transformation toward self-actualization. We identified a common theme in these three examples: The jar provides a safe space that allows transformation to occur during the journey toward self-actualization.

The individual psyche is born in an uroboric state in which the ego is contained in the Self. The psyche has an innate tendency to have the ego become completely separated from the Self and go through a development process toward an ideal self-actualization in which the ego-Self axis is made conscious (Edinger, 1972/2016). But sometimes, one can face the danger of the unconscious being disconnected from the conscious during the process. Therefore, one needs a safe space that would bring the unconscious to consciousness (Kalff, 2012). The jar, which was explored thoroughly in this paper, becomes the archetypal mother that safely contains the individual psyche, facilitating its transformation and healthy separation. The individual psyche requires a containing space during its transformation toward self-actualization, 
and this paper allowed us to see how people from different cultures have represented such symbolism of the jar through tales and other cultural elements.

\section{References}

Bang, B-S. (2002). White porcelain, pure white colored mind of Joseon Dynasty. Seoul: Dolbegae. Carson, D. A. (1991/2017). The gospel according to John. Seoul: Solomon. (Trans. into Korean). Cooper, J. C. (1978/1994). An illustrated encyclopedia of traditional symbols. Seoul: Kachibooks.

(Trans. into Korean).

Diel, P. \& Solotareff, J. (1988). Symbolism in the Gospel of John. CA: Harper and Row.

Edinger, E. F. (1972/2016). Ego and archetype. Seoul: Hakjisa. (Trans. into Korean). (1984/2016). The creation of consciousness. Seoul: Donhwamoon. (Trans. into Korean).

Han, S-I. (2003). Sacrament in the Gospel of John. (Master's thesis), Hanil University \& Presbyterian Theological Seminary, Wanju, Korea.

Henry, M. (2006). Matthew Henry's commentary. Goyang: Christian Digest. (Trans. into Korean). Ions, V. (2003). Egyptian mythology. Seoul: Bumwoosa. (Trans. into Korean).

Jeong, S-M. (2003). Study on Jung's psychological symbols in the Gospel of John. (Master's thesis), Hanshin University, Osan, Korea.

Kalff, D. (2012). Sanldplay. Seoul: Hakjisa. (Trans. into Korean).

Kang, S-N. (2013). The development of God's gift: law, wine, and the Holy Spirit. Theological Perspective (181), 2-39.

Kim, M. (2019). The water revealing the identity of Jesus in John's Gospel and new Pascha. (Master's thesis), Catholic University of Pusan, Busan, Korea.

Kim, W-K. (2005). Where, in what from, shall we meet again. Seoul: Whanki Museum.

Lee, H-B. (2012. 2. 8.). "5. Why do they put Sarira in a jar?", Beopbonews, http://www.beopbo.com/news/articleView.html?idxno=69341

(2012. 2. 21.). "6. Why are there many paintings of jars with flowers in 
Journal of Symbols \& Sandplay Therapy, Vol.10 No.2.

temples?”, Beopbonews, http://www.beopbo.com/news/articleView.html?idxno=69526

Lee, M-A. (2005). A study on the formative concept of the traditional symbols in Kim Hwan-ki's painting. (Master's thesis), Hongik Univeristy, Seoul, Korea.

Lee, N-M. (2010). Jung plays with Koreans riding on tigers. Seoul: Minumin.

Min, Y-S. (2005). A hundred fun old stories told by our grandmother. Seoul: Jayoomunhaksa.

Neumann, E. (2004/2010). Ursprungsgeschichte des Bewusstseins. Seoul: Analytical Psychology Center.

(Trans. into Korean).

Park. Y-T. (2010). Kim, Whan-Ki's white porcelain paintings and primitivism of magazine $<$ Mun Jang $>$. The Studies of Korean Literature 30, 315-346.

Rhi, B-Y. (2002). Self and self-actualization. Paju: Hangilsa. (2011). Analytical psychology: C. G. Jung's thoughts on mind. Seoul: Ilchokak.

Seo, S-H. (2019). A Study on the symbolic meanings of jars. Journal of Symbols \& Sandplay Therapy 101), 109-130.

Turner, B. A. (2005/2009). Handbook of sandplay therapy. Seoul: Hakjisa. (Trans. into Korean). Yoon, Y-Y. (2000). Our beautiful porcelain. Seoul: Hakgogae. 